\title{
Networks that Cross the Boundaries of the Classroom: A Quasi- Experimental Study of University Students
}

\author{
José Alberto Benítez-Andrades ${ }^{1}$, Isaías García ${ }^{2}$, Carmen Benavides ${ }^{1}$, Javier Pérez- \\ Paniagua $^{3}$, Pilar Marqués-Sánchez ${ }^{4}$, Mercedes Reguera ${ }^{4}$ \\ ${ }^{1}$ SALBIS Research Group, Dept. of Electric, Systems and Automatics Engineering, \\ University of León, Spain, ${ }^{2}$ SECOMUCI Research Groups, Escuela de Ingenierías Industrial \\ e Informática, Universidad de León, Spain, ${ }^{3} \mathrm{M}$.Sc. student, University of León ${ }^{4}$ Faculty \\ Health of Science, SALBIS Research Group, University of León, Spain.
}

\begin{abstract}
Currently there is a trend towards facilitating multidisciplinary research and collaborations between different faculties and/or multi-university collaboration. In order to achieve standardization, we believe that this culture should begin with the teaching-learning processes. This research has investigated collaborative work between nursing students and computer engineering students. To analyze the group response, an analysis of the contacts was carried out through Social Network Analisys, pre- and postintervention. The student networks analyzed were friendship, collaboration and negative networks. The results show that the intervention had a positive impact on networks among students, creating greater cohesiveness due to the resources they shared. The research adds useful evidence for proposing innovative and multidisciplinary strategies in terms of networks.
\end{abstract}

Keywords: Social Networks; collaboration; intervention; university students; innovation learning 


\section{Introduction}

The use of technology can be useful in the teaching-learning process for nursing students. Different studies have shown that developing technological competencies could help the student to increase their interconnectivity in order to receive support in academic tasks and even in social and personal areas (Todhunter, 2015). Currently, there is a trend to create academic structures that promote nursing in global health. For this purpose, some initiatives have been developed in the USA to facilitate multidisciplinary research and collaborations between different faculties and / or multi-university collaborations (Gimbel et al, 2017). Thus, we consider that technology and anything linked to computer engineering could add value to health care, given that it is usual for nurses to know patients' needs but not how to propose technological solutions, whereas computer engineers can quickly find such solutions. For this reason, a multidisciplinary teaching experience is proposed, in cooperation with nursing and engineering students.

There are previous experiences based on education and contacts, such as the case of peer education, which establishes cooperation and counseling between two students, both within the same and different courses, in which older students teach and advise younger ones (Farrokhi et al, 2018). But there is a lack of studies that delve into the analysis of how those relationships between two people build larger networks through which knowledge, confidences, concerns, motivations, etc. are shared, and which could be organized in order to achieve good academic performance and well-being within the university community. Resources that are transferred through the contacts, and their optimization, can be analyzed through Social Network Analysis (SNA).

SNA is an analytical method which studies the relationship between different social entities and the repercussion of those links (Wasserman et al., 1994). Its main elements are nodes and relationships. In SNA the concept of actor does not only refer to how a node acts, but it also emphasizes how the node is examined in terms of relational behavior within the social network (Lozares, 1996). On this basis, nodes can be connected through relationships and, therefore, their objectives and goals can also be connected (Robins, 2015). This perspective is extremely useful when approaching educational strategies in the university context, since we would be ablel to explore what kind of positions or structures would allow for better academic performance and, in general, a very satisfactory university life experience. The importance of connectivity is added to the importance of structure. Connectivity is a process of interpersonal transmission between those who have or have had social ties (Borgatti and Foster, 2003). Thus, resources, such as friendship, help, and even negative relationships can be transferred.

There is ample literature in the educational field on the application of SNA. Topics such as the 'adverse effects of students' stuttering on their social and emotional functioning at school' 
(Adriaensens et al, 2017), 'class collaborations to create multimedia stories’ (Liu et al 2017), and 'case evaluations of clinical studies by doctors' (Saqr, et al, 2018), among others, have been addressed.

Therefore, the general objective of this study is to assess the impact that a teaching-learning intervention can have on the networks of nursing and engineering students at university. At a general level, this study aims to compare network behavior before and after cooperative work is carried out between both groups of students. Cooperative work is influenced by structural mechanisms of networks (Jostad et al, 2013), which in turn, influences the dynamics of the network. Thus, we are assuming that a network is not static, and that its dynamics can also be channeled and optimized to achieve the best results in students.

In summary, with this research we intend to answer the following question: Can intervention in the teaching-learning process change the network of relationships among students?

\section{Methods}

\subsection{Context}

The study was carried out at the University of León, Spain. The University of León promotes educational innovation processes by means of annual calls. This research project was presented for one such call and selected as a proposal for educational innovation. The professors who led this educational-innovation project taught two subjects: Nursing Management (Nursing Degree) and Semantic Web (Computer Engineering). Student groups consisted of 3-4 nursing students and 3-4 computer engineering students. The nursing and engineering students were on different campuses separated by $100 \mathrm{~km}$, so their usual contact was through telephone calls, online chats, etc. In each group, the nursing students were supposed to work on a need arising from the patients, and the engineering students to present a technological proposal. Based on this, the following plan was established:

Stage 1. Evaluate networks between nursing and engineering students on the first day of work. On the first day of work, students and professors had a face-to-face session at the Ponferrada Campus so that the students could introduce themselves to each other, as well as be presented with the methodology and objectives of the work. They were also given information on when they would have to finish the work, how they would give their presentation and what the evaluation criteria would be. Regarding the presentation, the process was to be as follows: Nursing students would present the work of the engineering students, and vice versa. This decision was made by the professors because among competencies to be evaluated was "communication", which implied a facility to communicate with the rest of society, i.e., not exclusively with people from their professional environment. For this reason, engineering students, for example, would have to explain their contents to 
nursing students in such a way that the latter would understand them and subsequently be ablel to present them, and vice versa.

Stage 2. For 40 days students worked on each part of the assignment in their respective subjects, keeping contacts with fellow students via online chats, phone calls, emails, etc. During this phase they were continually supervised by the professors. Nursing and engineering professors also had contact with each other in order to assess the whole process and remain coordinated.

Stage 3. On the last day, the students presented their work via videoconference, from their respective campuses, namely the Ponferrada Campus (Nursing students) and the Vegazana Campus (Engineering students). On that day the professors evaluated each presentation using a rubric containing criteria related to content, structure and clarity of the presentation, communication skills, innovation and the impact of the proposal.

\subsection{Subjects}

Participating were 50 students, 26 3rd year nursing students and 24 4th year computer engineering students. Two professors collaborated in each subject area. The students were divided into 9 workgroups. They had to address issues related to cybersecurity and health monitoring, loneliness and artificial intelligence, and nurse-bloggers who cater to young people with problems related to addictions or obesity.

\subsection{Study design}

This is a quasi-experimental descriptive study with pre and post-intervention. On the first day of class the subjects were monitored in real time using SNA. On the last day of class, they were monitored again to assess the dynamics of the networks.

\subsection{Data collection}

To collect the data anonymously, a custom multiplatform application was programmed making use of web technologies (PHP, HTML5, CSS, Javascript) and a MySQL database system. The web application was hosted on a server which allowed students to connect to it through a URL, and through a user-authentication system students were able to answer different questionnaires, some of them having the objective of collecting engagement and socio-demographic data from the students (Benítez et al., 2017). The data was oraginzed with Excel. UCINET was used to calculate the structural variables. 


\subsection{Data analysis}

The networks in which structural patterns were analyzed were:

Friendship Network. Which of the following fellow students do you consider as a friend?

Collaboration Network. Which of the following fellow students do you ask for help when a problem / doubt / difficulty in the academic field arises?

Negative Network. Which of the following fellow students do you AVOID interacting with?

\subsection{Research ethics}

The students were informed verbally of the study-objectives and signed an informed consent form. Confidentiality of data and anonymity of the subjects were maintained at all times. The study was approved by the University Ethics Committee (ETICA-ULE- -026-2018).

\section{Results and discussion}

The findings show that the networks are dynamic and do not correspond to a static image (Figures 1, 2 and 3). In particular, our networks are less densely connected among students before starting a cooperative activity than they are at the end of it. But this is not only true among students of different degrees (nursing, engineering), which would be logical, but also among students of the same degree. This result is in line with previous studies that have shown that people's attachment style can be altered by dyadic influence, so that individuals manage their social networks (Gillat et al, 2017).

The question is what kind of attention should be given to these dyadic relationships, and to the resources that are transferred, such as friendship, help, negative relationships, etc. This discussion is interesting because the results could be influenced by the structure and dynamics of the networks. Indeed, the most popular students create norms in the classroom, and can influence the processes of friendship that are created around achievements and objectives to be reached (Laninga-Wijen et al, 2018). In this sense, it has also been found that the matching of students and the formation of larger networks has a positive impact on their engagement, and this, in turn, on academic performance (Liu et al, 2017, Fernández-Martínez et al, 2017). Even negative or toxic relationships could have some positive impact, depending on whether the negative ties are direct or indirect, and how they are combined with other networks (Marineau et al, 2016). 
Networks that Cross the Boundaries of the Classroom: A Quasi-Experimental Study of University Students
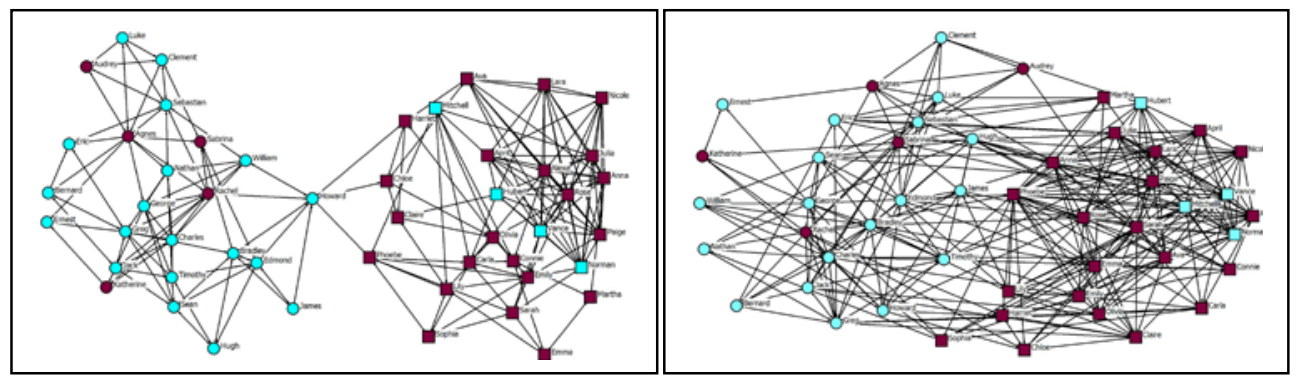

Figure 1. Frienship Network Pre-intervention and post-intervention

Blue circle node: Male engineering student; Bordeaux circle node: Female engineering student Blue square node: Male nursing student; Bordeaux square node: Female nursing student
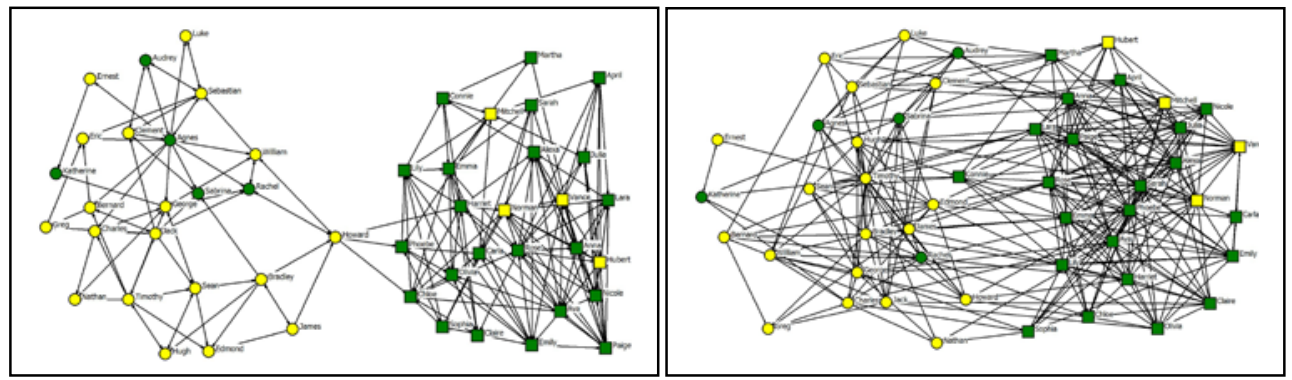

Figure 2. Collaboration Network pre-intervention and post-intervention

Yellow circle node: Male engineering student; Green circle node: Female engineering student Yellow square node: Male nursing student; Green square node: Female nursing student
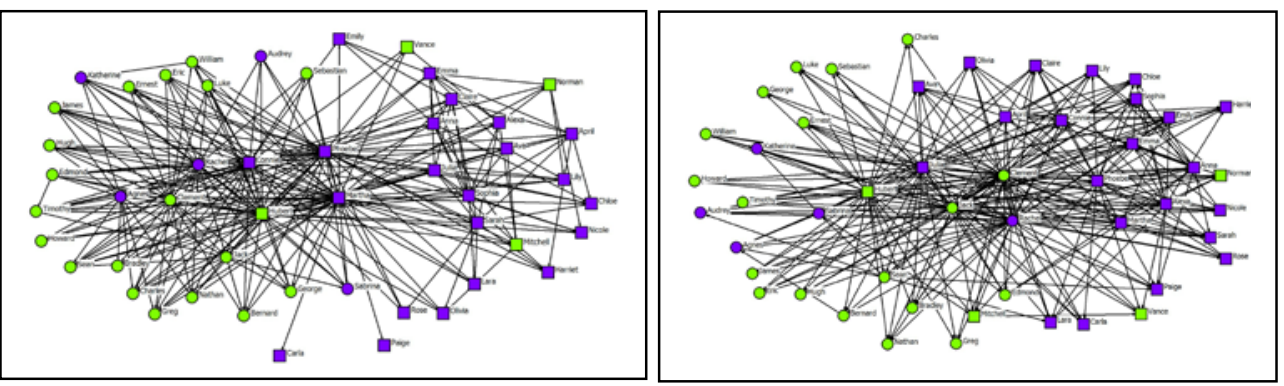

Figure 3. Negative Network pre-intervention and post-intervention

Green circle node: Male engineering student; Mallouc circle node: Female engineering student Green square node: Male nursing student; Mallouc square node: Female nursing student 


\section{Conclusion and limitations}

Our findings add evidence to the small core of studies that addresses positive and negative networks in the academic field. SNA can be used to design the most appropriate strategies in teaching-learning processes both within and outside the classroom. The ties and relationships cross the boundaries of the classroom. Students form cliques that could have an influence on the academic climate (Kamiri et al, 2018). On the other hand, these experiences also have a very positive impact among professors. In our case, the professors started a relationship that has been cemented, leading to collaboration in the same research group, the SALBIS group (www.salbis.es). This type of collaboration achieves great added value, because the heterogeneous relationship that professors model set a standard for their own students, so that they normalize interdisciplinary collaboration.

An important limitation to this study is that it does not include other structural variables, which will be taken into consideration in future lines of research.

\section{References}

Adriaensens, S., Van Waes, S., \& Struyf, E. (2017). Comparing acceptance and rejection in the classroom interaction of students who stutter and their peers: A social network analysis. Journal of Fluency Disorders, 52, 13-24. https://doi.org/10.1016/j.jfludis.2017.02.002

Anders, A. D. (2018). Networked learning with professionals boosts students' self-efficacy for social networking and professional development. Computers and Education, 127(August), 13-29. https://doi.org/10.1016/j.compedu.2018.08.009

Benítez, J.A., Labra, J.E., Quiroga, E., Martín, V., García, I., Marqués-Sánchez, P., \& Benavides, C. (2017). A Web-Based Tool for Automatic Data Collection, Curation, and Visualization of Complex Healthcare Survey Studies including Social Network Analysis. Computational and Mathematical Methods in Medicine, ID 2579848, 8 pag. http://doi.org/10.1155/2017/2579848

Carpiano, R. M., \& Fitterer, L. M. (2014). Questions of trust in health research on social capital: What aspects of personal network social capital do they measure? Social Science and Medicine, 116, 225-234. https://doi.org/10.1016/j.socscimed.2014.03.017

Claros, I., Cobos, R., \& Collazos, C. A. (2016). An Approach Based on Social Network Analysis Applied to a Collaborative Learning Experience. IEEE Transactions on Learning Technologies, 9(2), 190-195. https://doi.org/10.1109/TLT.2015.2453979

Farrokhi, S., Ghasemi, S. S., Ahmadipanah, V., \& Bagheri-Saweh, M. I. (2018). An investigation into the effect of peer-education on learning catheterization skill among nursing students of Medical Sciences Faculty in 2016-17. Medical Science, 22(91), 295300. 
Fernández-Martínez, E., Andina-Díaz, E., Fernández-Peña, R., García-López, R., FulgueirasCarril, I., \& Liébana-Presa, C. (2017). Social networks, engagement and resilience in university students. International Journal of Environmental Research and Public Health, 14(12). https://doi.org/10.3390/ijerph14121488

Gillath, O., Karantzas, G. C., \& Selcuk, E. (2017). A Net of Friends: Investigating Friendship by Integrating Attachment Theory and Social Network Analysis. Personality and Social Psychology Bulletin, 43(11), 1546-1565. https://doi.org/10.1177/0146167217719731

Gimbel, S., Kohler, P., Mitchell, P., \& Emami, A. (2017). Creating academic structures to promote nursing's role in global health policy. International Nursing Review, 64(1), 117 125. https://doi.org/10.1111/inr.12338

Karimi, F., \& Matous, P. (2018). Mapping diversity and inclusion in student societies: A social network perspective. Computers in Human Behavior, 88, 184-194. https://doi.org/10.1016/j.chb.2018.07.001

Jostad, J., Sibthorp, J., \& Paisley, K. (2013). Understanding groups in outdoor adventure education through social network analysis. Australian Journal of Outdoor Education, 17(1), 17-31. https://doi.org/http://dx.doi.org/10.1016/S0009-9260(82)80195-5

Labianca, G., \& Brass, D. J. (2006). Exploring the social ledger: Negative relationships and negative asymmetry in social networks in organizations. Academy of Management Review, 31(3), 596-614. https://doi.org/10.5465/AMR.2006.21318920

Laninga-Wijnen, L., Ryan, A. M., Harakeh, Z., Shin, H., \& Vollebergh, W. A. M. (2018). The moderating role of popular peers' achievement goals in 5th-and 6th-graders' achievement-related friendships: A social network analysis. Journal of Educational Psychology, 110(2), 289-307. https://doi.org/10.1037/edu0000210

Liébana-Presa, C., Andina-Díaz, E., Reguera-García, M. M., Fulgueiras-Carril, I., BermejoMartínez, D., \& Fernández-Martínez, E. (2018). Social network analysis and resilience in university students: An approach from cohesiveness. International Journal of Environmental Research and Public Health, 15(10), 2119. https://doi.org/10.3390/ijerph15102119

Liu, C. C., Chen, Y. C., \& Diana Tai, S. J. (2017). A social network analysis on elementary student engagement in the networked creation community. Computers and Education, 115(300), 114-125. https://doi.org/10.1016/j.compedu.2017.08.002

Lozares, C., \& Sumario, R. (1996). La teoria de redes sociales. Papers, 48, 103-126. https://doi.org/10.5565/rev/papers/v48n0.1814

Marineau, J. E., Labianca, G. J., \& Kane, G. C. (2016). Direct and indirect negative ties and individual performance. Social Networks, 44, 238-252. https://doi.org/10.1016/j.socnet.2015.09.003

Marqués, P. (2010). Influencia de las redes sociales en el rendimiento de las organizaciones: un estudio en el sector sanitario (tesis doctoral). León: Universidad de León.

Saqr, M., Fors, U., \& Tedre, M. (2018). How the study of online collaborative learning can guide teachers and predict students' performance in a medical course. BMC Medical Education, 18(1), 1-14. https://doi.org/10.1186/s12909-018-1126-1 
Todhunter, F. (2015). Using principal components analysis to explore competence and confidence in student nurses as users of information and communication technologies. Nursing Open, 2(2), 72-84. https://doi.org/10.1002/nop2.19 